\title{
Refractive errors in Cameroonians diagnosed with complete oculocutaneous albinism
}

This article was published in the following Dove Press journal:

Clinical Ophthalmology

20 July 2013

Number of times this article has been viewed

\section{André Omgbwa Eballé1,3 \\ Côme Ebana Mvogo ${ }^{2}$ \\ Christelle Noche ${ }^{4}$ \\ Marie Evodie Akono Zoua ${ }^{2}$ \\ Andin Viola Dohvoma ${ }^{2}$}

'Faculty of Medicine and

Pharmaceutical Sciences, University of

Douala, Douala, Cameroon, ${ }^{2}$ Faculty

of Medicine and Biomedical Sciences,

University of Yaoundé I, Yaoundé,

Cameroon; ${ }^{3}$ Yaoundé Gynaeco-

Obstetric and Paediatric Hospital,

Yaoundé, Cameroon; ${ }^{4}$ Faculty of

Medicine, Université des Montagnes,

Bangangté, Cameroon
Correspondence: André Omgbwa Eballé Ophthalmology Unit, Yaoundé GynaecoObstetric and Paediatric Hospital,

PO Box 4362, Yaoundé, Cameroon

Tel +23799654468

Fax +237 22224419

Email andyeballe@gmail.com
Background: Albinism causes significant eye morbidity and amblyopia in children. The aim of this study was to determine the refractive state in patients with complete oculocutaneous albinism who were treated at the Gynaeco-Obstetric and Paediatric Hospital, Yaoundé, Cameroon and evaluate its effect on vision.

Methods: We carried out this retrospective study at the ophthalmology unit of our hospital. All oculocutaneous albino patients who were treated between March 1, 2003 and December 31, 2011 were included.

Results: Thirty-five patients ( 70 eyes) diagnosed with complete oculocutaneous albinism were enrolled. Myopic astigmatism was the most common refractive error (40\%). Compared with myopic patients, those with myopic astigmatism and hypermetropic astigmatism were four and ten times less likely, respectively, to demonstrate significant improvement in distance visual acuity following optical correction.

Conclusion: Managing refractive errors is an important way to reduce eye morbidity-associated low vision in oculocutaneous albino patients.

Keywords: albinism, visual acuity, refraction, Cameroon

\section{Introduction}

Albinism is an inherited abnormality of melanin synthesis. Its clinical manifestations are related to the reduction or absence of pigmentation in the visual system and/or the skin and teguments. ${ }^{1}$ Albinism is a universal condition that demonstrates an incidence of one case per 20,000 births. ${ }^{2}$ Albinism is more common in black people, and its transmission is autosomal recessive in most cases. ${ }^{3}$

During the development of the optic system, melanin deficiency causes clinical manifestations such as foveal hypoplasia, strabismus, nystagmus, photophobia, and refractive errors. ${ }^{2}$ This explains the low visual acuity that presents from birth. The cellular integrity of the fovea in albino patients is not well understood, but important anatomical differences most likely underlie the phenotypic variability of this disease and may also affect patient responsiveness to therapeutic intervention. $^{4}$

McAllister et $\mathrm{al}^{4}$ reported that foveal morphology and cone specialization are variable in albino patients (based on examinations of the foveal pit and determination of photoreceptor outer segment elongation). According to Mohammad et al, ${ }^{5}$ the size of the outer segment of the photoreceptor is the strongest predictor of best corrected visual acuity in albino patients. 
Refractive errors are common in albino patients, and relatively high values are reported in the literature. ${ }^{6,7}$ In the African literature, very little data exists on the vision of oculocutaneous albino patients. Other authors ${ }^{8,9}$ studied ophthalmic disorders in all types of albinos between 2001-2007 in Douala, Cameroon. Here, our study focuses only on refractive errors in patients diagnosed with complete oculocutaneous albinism. The aim of this study, which was carried out at the ophthalmology unit of Yaoundé GynaecoObstetric and Paediatric Hospital, Yaoundé, Cameroon, was to determine the refractive states of albino patients with complete oculocutaneous albinism and any correlations with vision.

\section{Methods}

This retrospective study was carried out between March 1, 2003 and December 31, 2011. Data were collected from the medical records of all patients. All patients with complete oculocutaneous albinism $\geq 5$ years of age were included. Patients $<5$ years of age were excluded because it is difficult to obtain accurate measurements of their visual acuities. Patients with ocular albinism and the yellow mutant forms of oculocutaneous albinism were also excluded.

Patients were not classified as tyrosinase-positive or tyrosinase-negative due to the fact that tyrosinase hair bulb incubation tests were not performed as part of this study. Clinical evaluations included the following: evaluation of symptoms and past medical history; visual acuity testing using Snellen's tumbling E chart; and external clinical examination and slit-lamp examination of the anterior and posterior segments of the eyes, respectively. Intraocular pressure was measured using a non-contact tonometer (Topcon Medical Systems, Paris, France).

Diagnosis was based on the presence of the following conditions: iris transillumination, foveal hypoplasia, and retinal hypopigmentation in association with depigmentation of the skin, hair, and nails. ${ }^{10,11}$ Cycloplegic automatic refraction was performed using the RM-8000D system (Topcon Medical Systems). Cycloplegia was achieved with $0.5 \%$ tropicamide (Mydriaticum ${ }^{\circledR}$ ) and $0.5 \%$ cyclopentolate $\left(\right.$ Skiacol $\left.^{\circledR}\right)$. A drop of each was instilled alternately at 5-minutes intervals. A total of 3 instillations for each drug were made. Automatic refraction was performed for 45-60 minutes after the last instillation.

In this study, myopia is defined as spherical ametropia in which parallel light rays coming from infinity focus on a plane in front of the retina; hypermetropia refers to spherical ametropia in which parallel light rays coming from infinity focus on a plane behind the retina. ${ }^{12}$

Astigmatism refers to an optical system that does not produce a point image from a point object, as opposed to a stigmatic system which does produce a point image from a point object. Direct astigmatism is known as "with-the-rule" astigmatism when the radius of curvature of the vertical meridian is less than that of the horizontal meridian. In indirect or "against-the-rule" astigmatism, the radius of the curvature of the horizontal meridian is less than that of the vertical meridian. In oblique astigmatism, the principal meridians are perpendicular to each other and situated at $45^{\circ}$ and $135^{\circ}$. Astigmatism is considered "simple" when one focal line is on the retina, but this could be diagnosed as simple myopic or simple hypermetropic astigmatism depending if the other focal line is in front of or behind the retina, respectively. If both focal lines are found on the same side of the retina, this could be diagnosed as myopic or composed hypermetropic astigmatism. Mixed astigmatism is diagnosed when both focal lines are found on either side of the retina. ${ }^{12}$

The following variables were analyzed: age, sex, uncorrected distance visual acuity, automatic refraction, and best corrected distance visual acuity (CDVA). Ametropia was classified as myopia, hypermetropia, myopic astigmatism, hypermetropic astigmatism, or mixed astigmatism in order to avoid determination of the spherical equivalent.

There are four levels of visual function according to the International Classification of Diseases-10: normal vision (CDVA $\geq 3 / 10)$; moderate visual impairment $(1 / 10 \leq$ CDVA $<3 / 10)$; severe visual impairment $(1 / 20 \leq$ CDVA $<1 / 10)$; and blindness (CDVA $<1 / 20)$. Moderate and severe visual impairment were considered "low vision." Low vision together with blindness represents all types of visual impairments. ${ }^{13}$ This definition was used to classify visual impairment.

Table I Distribution of cases by age

\begin{tabular}{lll}
\hline Age (years) & $\mathbf{n}$ & Percentage (\%) \\
\hline $5-15$ & 25 & 71.43 \\
$16-25$ & 8 & 22.86 \\
$26-37$ & 2 & 5.10 \\
Total & 35 & 100.00 \\
Summarized measurements & Value \\
\hline Mean (years) & 12.30 \\
Standard deviation & 7.76 \\
95\% Cl for the mean & $10.45-14.15$ \\
Minimum (years) & 5 \\
Maximum (years) & 37 \\
\hline
\end{tabular}

Abbreviations: $\mathrm{n}$, number; $\mathrm{Cl}$, confidence interval. 
Table 2 Distance visual acuity analysis

\begin{tabular}{|c|c|c|c|}
\hline $\begin{array}{l}\text { Distance } \\
\text { VA }\end{array}$ & $\begin{array}{l}\text { Uncorrected } \\
\mathrm{n}(\%)\end{array}$ & $\frac{\text { Corrected }}{\mathrm{n}(\%)}$ & $\begin{array}{l}\text { WHO } \\
\text { definition }\end{array}$ \\
\hline$V A>3 / 10$ & $0(0)$ & 14 (20\%) & $\begin{array}{l}\text { No visual } \\
\text { impairment }\end{array}$ \\
\hline $\begin{array}{l}3 / 10> \\
V A \geq 1 / 10\end{array}$ & 49 (70\%) & 52 (74.3\%) & $\begin{array}{l}\text { Moderate visua } \\
\text { impairment }\end{array}$ \\
\hline $\begin{array}{l}1 / 10> \\
V A \geq 1 / 20\end{array}$ & 15 (2I.42\%) & $3(4.28 \%)$ & $\begin{array}{l}\text { Severe visual } \\
\text { impairment }\end{array}$ \\
\hline $\mathrm{VA}<\mathrm{I} / 20$ & $6(8.58 \%)$ & I (I.42\%) & Blindness \\
\hline $\begin{array}{l}\text { Mean distance } \\
\text { VA }\end{array}$ & $0.11 \pm 0.05$ & $0.15 \pm 0.08$ & $\begin{array}{l}\text { Moderately low } \\
\text { vision }\end{array}$ \\
\hline
\end{tabular}

Abbreviations: VA, visual acuity; n, number; WHO, World Health Organization.

Patients were divided into two groups: one group consisted of patients whose visual acuity improved following optical correction (group 1), and the other consisted of patients who did not demonstrate improvement (group 2).

Microsoft Excel 2007 (Microsoft Corporation, Redmond, WA, USA), CS Pro 3.3 (Informer Technologies, www. informer.com), and SPSS (IBM Corporation, Armonk, NY, USA) were used to perform all statistical analyses. Student's $t$-test was used to compare the means between the two groups, and analysis of variance was used to analyze multiple groups together. The Chi-square test, Pearson linear correlation test, and multivariate logistic regression were used to determine any relationships between variables. Tests were considered statistically significant when $P$-values $<0.05$ were determined.

\section{Results}

During the study period, 70 eyes in 35 patients were examined. More males $(n=20 ; 57 \%)$ than females $(n=15$; $47 \%$ ) were included, demonstrating a male:female sex ratio of 1.33.1. The mean age of the study population was $12.30 \pm 7.76$ years. Twenty-five patients $(71.43 \%)$ were between $5-15$ years of age, and the oldest patient was 37 years old (Table 1). Uncorrected distance visual acuity was $<1 / 20$ in six eyes $(8.58 \%),<3 / 10$ but $\geq 1 / 10$ in 49 eyes $(70 \%)$, and $<1 / 10$ but $\geq 1 / 20$ in 15 eyes $(21.42 \%)$. CDVA of one eye $(1.42 \%)$ was $<1 / 20$, thereby meeting the World Health Organization's definition for blindness. ${ }^{13}$ Fifty-two eyes $(74.3 \%)$ had CDVA $<3 / 10$ but $\geq 1 / 10$ and were classified as moderate visual impairment. However, three eyes ( $4.28 \%)$ had CDVA $<1 / 10$ but $\geq 1 / 20$ and were classified as severe visual impairment. Fourteen eyes (20\%) had a CDVA $\geq 3 / 10$ (Table 2).

According to the examinations that used the Snellen's tumbling E chart, the mean uncorrected distance visual acuity was $0.11 \pm 0.05$. Mean visual acuity rose to $0.15 \pm 0.08$ with optical correction. There was a positive linear correlation between uncorrected and corrected visual acuities, demonstrating a Pearson linear correlation coefficient of $0.727(P=0.000$; Table 3$)$. Myopic astigmatism was the most common refractive error $(\mathrm{n}=28 ; 40 \%)$, followed by myopia $(\mathrm{n}=20 ; 28.6 \%)$. Hyperopia and hyperopic astigmatism were diagnosed in ten eyes each $(14.3 \%)$, and mixed astigmatism was diagnosed in two eyes (2.8\%; Table 4). All cases of astigmatism were diagnosed as "with-the-rule" and ranged from 0.50-6.50 diopters, demonstrating a mean of $3.62 \pm 1.8$ diopters. Subjective refraction was analyzed in all patients, leading to improvement in distance visual acuity by one or two lines on the Snellen's tumbling E chart in 51.42\% of patients ( $n=18$ of 35 patients; 36 eyes were analyzed). However, distance visual acuity could not be improved in $48.58 \%$ of patients $(n=17)$ diagnosed with amblyopia. The mean age of the patients whose distance visual acuity improved with optical correction was $13 \pm 8.99$ years (group 1 patients), in comparison with $11.56 \pm 6.26$ years for patients whose distance visual acuity could not be improved using optical correction (group 2 patients; $P=0.442$; Table 5). The degree of refractive error did not influence corrected visual acuity - instead, the type of refractive error statistically influenced corrected visual acuity. Myopic and hyperopic patients demonstrated improvements in distance visual acuity following optical correction, while astigmatic patients did not demonstrated improvement regardless of the type of the astigmatism (Table 6).

\section{Discussion}

Visual impairment in patients with complete oculocutaneous albinism worsens the emotional and social problems associated with this condition. This leads to greater stigmatization and

Table 3 Analysis of uncorrected and corrected distance visual acuity measured in all eyes $(n=70)$

\begin{tabular}{lllllll}
\hline & Minimum & Maximum & Median & $\begin{array}{l}\text { Mean } \pm \text { standard } \\
\text { deviation }\end{array}$ & $\begin{array}{l}\text { 95\% confidence } \\
\text { interval }\end{array}$ \\
\hline Uncorrected & 0.02 & 0.20 & 0.10 & $0.11 \pm 0.05$ & $0.09-0.12$ & 0.000 \\
Corrected & 0.02 & 0.30 & 0.10 & $0.15 \pm 0.08$ & $0.13-0.17$ \\
\hline
\end{tabular}

Note: *Determined using Student's $t$-test.

Abbreviation: $\mathrm{n}$, number. 
Table 4 Refractive errors analysis

\begin{tabular}{|c|c|c|c|c|c|c|}
\hline Refractive error & $\mathbf{n}$ & $\%$ & $\begin{array}{l}\text { Mean } \\
\text { power (D) }\end{array}$ & $\begin{array}{l}\text { Standard } \\
\text { deviation }\end{array}$ & $\begin{array}{l}95 \% \text { confidence } \\
\text { interval }\end{array}$ & $P *$ \\
\hline Myopia & 20 & 28.6 & 7.74 & $4.4 I$ & $5.67-9.80$ & 0.000 \\
\hline MA & 28 & 40 & 3.72 & 1.47 & $3.15-4.29$ & \\
\hline Hypermetropia & 10 & 14.3 & 3.80 & 2.96 & $1.68-5.92$ & \\
\hline $\mathrm{HA}$ & 10 & 14.3 & 3.58 & 2.17 & $2.02-5.13$ & \\
\hline Mixed astigmatism & 2 & 2.8 & 2.75 & 0.35 & -0.43 to 5.93 & \\
\hline Total & 70 & 100 & 4.83 & 3.38 & $4.03-5.64$ & \\
\hline
\end{tabular}

Note: *Determined using ANOVA.

Abbreviations: $n$, number; D, diopters; MA, myopic astigmatism; HA, hypermetropic astigmatism.

poor integration into society because albinism is still considered taboo in Cameroon despite its relatively common worldwide distribution and incidence of one case per 20,000 births. ${ }^{2}$

Refractive errors are common in oculocutaneous albino patients. Some studies report hypermetropia as the most common refractive error, ${ }^{2,714}$ while others report myopia. ${ }^{6,15}$ In a recent study of the refractive profiles of patients with oculocutaneous albinism, Yahalom et al ${ }^{16}$ reported astigmatism and hypermetropia as the most common refractive errors. In this study, myopic astigmatism was the most common, representing $40 \%$ of patients. This is similar to the results reported by Mvogo et $\mathrm{al}^{8}$ who reported that $61.9 \%$ of albino patients develop myopic astigmatism. This is contrary to studies on the general Cameroonian population that report hypermetropia as the most common refractive error. ${ }^{17-19}$

Astigmatism in albino patients, as reported in the literature, is generally classified as with-the-rule and highpower, ${ }^{7,20-22}$ and our results are in agreement with this. Patients diagnosed with with-the-rule astigmatism demonstrated a mean power of 3.62 diopters. Optical correction did not improve distance visual acuity, regardless of the type of astigmatism. This is contrary to myopia, in which there was a moderate but statistically significant improvement in distance visual acuity. Multivariate logistic regression modeling (Table 5) shows that oculocutaneous albino patients with myopic astigmatism are about four times less likely to demonstrate improvement in distance visual acuity following correction in comparison with myopic patients. Similarly, patients diagnosed with hyperopic astigmatism are nearly ten times less likely to have their distance visual acuity improved in comparison with myopic oculocutaneous albino patients.

These improvements in the distance visual acuities of several patients with eyeglasses corroborate the data reported in the literature. ${ }^{10,23}$ Although the improved visual acuities of these patients largely remain below normal, it does, however, improve the quality of life of these patients. Albinism is an important cause of low vision, accounting for 5\% of low-vision cases worldwide. ${ }^{24}$ Low vision in oculocutaneous albino patients can also be due to nystagmus or low macular cone density. ${ }^{25-27}$ Considering the fact that the majority $(71.43 \%)$ of our patients were between 5-15 years of age, albinism can be considered one of the leading causes of childhood amblyopia and educational retardation in Cameroon. In a study carried out in 2000, Bella et $\mathrm{al}^{28}$ reported that $7.5 \%$ of cases of blindness among children aged $0-5$ years are associated with oculocutaneous albinism. Similarly, Noche et $\mathrm{al}^{29}$ reported in 2010 that $5 \%$ of patients in schools for the visually impaired children in Yaoundé were diagnosed with low vision due to albinism. ${ }^{29}$

Developing countries also experience problems due to low socioeconomic standards. This may hinder accessibility to quality health care, especially among patients with low vision, and most especially among those with oculocutaneous albinism. This situation is further compounded by the fact that oculocutaneous albino patients have difficulties integrating into society. Low economic standards also hinder the acquisition of the up-to-date equipment needed for the optimal management of low vision.

This study is limited by the small sample size and the fact that autorefraction was used to determine the refrac-

Table 5 Mean ages of the patients with and without improvements in visual acuity

\begin{tabular}{lllllll}
\hline Evolution of VA & Mean CDVA & $\mathbf{n}$ & Mean age $(\mathbf{y})$ & Standard deviation & $\mathbf{9 5 \%} \mathbf{C l}$ & $9.96-16.04$ \\
\hline GI & $0.20 \pm 0.09$ & 36 & 13.00 & 8.99 & 0.442 \\
G2 & $0.11 \pm 0.04$ & 34 & 11.56 & 6.26 & $9.38-13.74$ \\
Total & $0.15 \pm 0.08$ & 70 & 12.30 & 7.76 & $10.41-14.13$ \\
\hline
\end{tabular}

Notes: *Determined using Student's t-test. GI: distance VA was improved with optical correction. G2: distance VA could not be improved with optical correction. Abbreviations: VA, visual acuity; CDVA, corrected distance visual acuity; Cl, confidence interval; GI, group I; G2, group 2; y, years 
Table 6 Multivariate logistic regression modeling

\begin{tabular}{lllll}
\hline Variable & Coefficient & Odds ratio & $95 \% \mathbf{C l}$ & $\mathbf{P}^{*}$ \\
\hline Diopters & -0.04 & 0.96 & $0.78-1.18$ & 0.695 \\
Age & 0.03 & 1.03 & $0.96-1.1 \mathrm{I}$ & 0.384 \\
$\begin{array}{l}\text { Refractive error } \\
\text { Myopia }\end{array}$ & Reference & Reference & Reference & Reference \\
MA & -1.35 & 0.26 & $0.06-1.17$ & 0.049 \\
Hypermetropia & 0.43 & 1.54 & $0.22-11.04$ & 0.666 \\
HA & -2.27 & 0.10 & $0.01-0.76$ & 0.026 \\
Mixed & - & - & - & - \\
$\quad$ astigmatism & & & & \\
\hline
\end{tabular}

Note: *The dependent variable was improvement in visual acuity.

Abbreviations: $\mathrm{Cl}$, confidence interval; $\mathrm{MA}$, myopic astigmatism; $\mathrm{HA}$, hypermetropic astigmatism.

tion statuses of our patients. Nystagmus is common in oculocutaneous albino patients and could have led to inaccurate measurements.

\section{Conclusion}

Complete oculocutaneous albinism is a condition that causes low vision. Myopic astigmatism and myopia were the most common refractive errors identified in this series. Optical correction is an important method for improving distance visual acuity in these patients.

\section{Disclosure}

The authors report no conflicts of interest in this work.

\section{References}

1. Grønskov K, Ek J, Brondum-Nielsen K. Oculocutaneous albinism. Orphanet J Rare Dis. 2007;2:43.

2. Wildsoet CF, Oswald PJ, Clark S. Albinism: its implications for refractive development. Invest Ophthalmol Vis Sci. 2000;41(1):1-7.

3. Goddé-Jolly D, Dufier JL. Ophtalmologie Pédiatrique. [Paediatric Ophthalmology] Paris, France: Masson; 1992:425-429.

4. McAllister JT, Dubis AM, Tait DM, et al. Arrested development: high-resolution imaging of foveal morphology in albinism. Vision Res. 2010;50(8):810-817.

5. Mohammad S, Gottlob I, Kumar A, et al. The functional significance of foveal abnormalities in albinism measured using spectral-domain optical coherence tomography. Ophthalmology. 2011;118(8):1645-1652.

6. Dickerson CM, Abadi RV. Corneal topography of humans with congenital nystagmus. Ophthalmic Physiol Opt. 1984;4(1):3-13.

7. Nathan J, Kiely PM, Crewther SG, Crewther DP. Disease-associated visual image degradation and spherical refractive errors in children. $\mathrm{Am}$ J Optom Physiol Opt. 1985;62(10):680-688.

8. Mvogo CE, Bella-Hiag AL, Ellong A, Mbarga BM. Visual problems in albinos: a hospital study carried out at the Douala General Hospital. Sante. 1999;9(2):89-91. French.

Clinical Ophthalmology

\section{Publish your work in this journal}

Clinical Ophthalmology is an international, peer-reviewed journal covering all subspecialties within ophthalmology. Key topics include: Optometry; Visual science; Pharmacology and drug therapy in eye diseases; Basic Sciences; Primary and Secondary eye care; Patient Safety and Quality of Care Improvements. This journal is indexed on Submit your manuscript here: http://www.dovepress.com/clinical-ophthalmology-journal
9. Ebana CM, Eballé AO, Ebana SR, Ellong A, Epée E, Bella AL. Anomalies oculaires des albinismes oculo-cutanés en milieu camerounais. [Ocular anomalies of oculo-cutaneous albinism in Cameroon]. Revue Soao. 2011;2:7-12.

10. Abadi R, Pascal E. The recognition and management of albinism. Ophthalmic Physiol Opt. Jan 1989;9(1):3-15.

11. Summers CG. Vision in albinism. Trans Am Ophthalmol Soc. 1996;94: $1095-1155$.

12. Wary P, Maÿ. Ocular Refraction. Encyl Med Chir Ophthalmology. 2007. 21-070-A-10.

13. World Health Organization. Consultation on Development of Standards for Characterization of Vision Loss and Visual Functioning. Geneva, Switzerland: World Health Organization; 2003. Available from: http://apps.who. int/iris/bitstream/10665/68601/1/WHO_PBL_03.91.pdf. Accessed.

14. Stärk N. Refractive errors in visually handicapped children. Klin Monbl Augenheilkd. 1987;191(5):397-402. German.

15. Spedick MJ, Beauchamp GR. Retinal vascular and optic nerve abnormalities in albinism. J Pediatr Ophthalmol Strabismus. 1986;23(2):58-63.

16. Yahalom C, Tzur V, Blumenfeld A, et al. Refractive profile in oculocutaneous albinism and its correlation with final visual outcome. Br J Ophthalmol. 2012;96(4):537-539.

17. Eballe AO, Bella LA, Owono D, Mbome S, Mvogo CE. Eye disease in children aged 6 to 15 years: a hospital-based study in Yaounde. Sante. 2009;19(2):61-66. French.

18. Ebana Mvogo C, Bella-Hiag AL, Epesse M. Strabismus in Cameroon. J Fr Ophtalmol. 1996;19(11):705-709. French.

19. Ebana Mvogo C, Bella-Hiag AL, Ellong A. Place de la correction optique dans le traitement de la limbo-conjonctivite endémique des tropiques. [Place of the optical correction in the treatment of the tropical endemic limbo-conjunctivitis]. Coup d'œil Ophtalmol. 1995;11:13-16. French.

20. GrosvenorTP, Flom MC, editors. Refractive Anomalies: Research and Clinical Applications. Boston, MA: Butterworth-Heinemann; 1991:146-173.

21. Pérez-Carpinell J, Capilla P, Illueca C, Morales J. Vision defects in albinism. Optom Vis Sci. 1992;69(8):623-628.

22. Jacobson SG, Mohindra I, Held R, Dryja TP, Albert DM. Visual acuity development in tyrosinase negative oculocutaneous albinism. Doc Ophthalmol. 1984;56(4):337-344.

23. Anderson J, Lavoie J, Merrill K, King RA, Summers CG. Efficacy of spectacles in persons with albinism. JAAPOS. 2004;8(6):515-520.

24. Kassir M, Dogredingao DN. L'albinisme dans la province centrale du Cameroun: du diagnostic au conseil génétique. [Albinism in the Centre Province of Cameroon: from diagnosis to genetic counseling.] Médecine d'Afrique Noire. 1998;45:457-461.

25. Oetting WS, Summers CG, King RA. Albinism and the associated ocular defects. Metab Pediatr Syst Ophthalmol. 1994;17(1-4):5-9.

26. Abplanalp P, Bedell $\mathrm{H}$. Visual improvement in an albinotic patient with an alteration of congenital nystagmus. Am J Optom Physiol Opt. 1987;64(12):944-951.

27. Wilson HR, Mets MB, Nagy SE, Kressel AB. Albino spatial vision as an instance of arrested visual development. Vision Res. 1988;28(9):979-990.

28. Bella LA, Eballea AO, Kouam JM. Bilateral blindness and visual impairment in children aged 0-5 years in the women's and children's hospital of Yaounde. Sante. 2010;20(1)1:35-39. French.

29. Noche CD, Bella AL. Frequency and causes of blindness and visual impairment in schools for the blind in Yaoundé (Cameroon). Sante. 2010;20(3):133-138. French.

\section{Dovepress}

PubMed Central and CAS, and is the official journal of The Society of Clinical Ophthalmology (SCO). The manuscript management system is completely online and includes a very quick and fair peer-review system, which is all easy to use. Visit http://www.dovepress.com/ testimonials.php to read real quotes from published authors. 